\title{
Ti-Mo Alloys: Corrosion Study in Solutions Simulating Commercial Gels
}

\author{
Aline Varella Rodrigues*, Antonio Carlos Guastaldi \\ Department of Physical Chemistry, Biomaterials Group of Institute of Chemistry, Universidade Estadual Paulista “Júlio \\ de Mesquita Filho" (UNESP), Araraquara-SP, Brazil \\ *Corresponding Author: Aline Varella Rodrigues; Corresponding address: Rua Prof. Francisco Degni, n. 55, ZIP Code: \\ 14800-060; Araraquara-SP, Brazil; E-mail address: alinevarellarodrigues@gmail.com
}

\section{ABSTRACT}

Regarding to the influence of chloride and fluoride ions on the corrosion resistance, the electrochemical behavior of Ti alloys has been deeply studied. In this work, the main goal was to investigate the electrochemical behavior of cp-Ti and Ti-Mo alloys containing 6, 10 and $15 \mathrm{wt} \%$ of Mo concentrations. All the samples were immersed in different solutions, such as $0.15 \mathrm{~mol} \mathrm{~L}^{-1} \mathrm{Na}_{2} \mathrm{SO}_{4}, 0.15 \mathrm{~mol} \mathrm{~L}^{-1}$ Ringer, $0.15 \mathrm{~mol} \mathrm{~L}^{-1}$ Ringer plus $0.036 \mathrm{~mol} \mathrm{~L}^{-1} \mathrm{NaF}$ and $0.036 \mathrm{~mol}$ $\mathrm{L}^{-1} \mathrm{NaF}$. Simulating the commercial fluorinated gels, the NaF solutions naturally-aerated were prepared with $1450 \mathrm{ppm}$ of fluoride ions. The electrochemical techniques applied in this work were the open-circuit potential, cyclic voltammetry, besides the technique for chemical identification, which was X-ray photoelectron spectroscopy. The formation and growth of $\mathrm{TiO}_{2}$ and $\mathrm{MoO}_{2}$ were identified, without pitting corrosion. The electrochemical stability and the corrosion resistance of the Ti-Mo alloys decreased in the solutions containing chloride and fluoride ions, with an appreciative decrease especially in the fluorinated medium. The Ti-Mo alloy with higher Mo content concentration was the material with higher corrosion resistance. Therefore, it is a promising candidate as a biomaterial, once the osseointegration needs a satisfactory corrosion resistance for being achieved.

Keywords: Thin Films; Corrosion Resistance; Metal and Alloys; Photoelectron Spectroscopies

\section{Introduction}

It is well known that titanium and its alloys present a high corrosion resistance in severe corrosive environments, besides an excellent biocompatibility. During the titanium alloy exposure to the halide-containing electrolytes, the oxide films spontaneously developed are susceptible to the pitting corrosion. It is a localized corrosion that is very harmful because it causes a corrosive attack that penetrates into the matrix of the alloy and makes the mechanical properties weaker. Besides the good corrosion resistance of the titanium alloys, their wide application is explained by their biocompatibility and mechanical properties as low Young's modulus, high yield and tensile strength ${ }^{[1,2]}$.

The corrosion phenomena is classified in pitting, galvanic coupling, crevice corrosion, fretting corrosion and corrosion fatigue, which are observed in conventional implants, such as implants made of stainless steel, Co-Cr alloys or commercial pure Titanium (cp-Ti), and Ti-6Al-4V [3]. The passivation and re-passivation prevent or inhibit that phenomena in the metallic implant materials, controlling the initiation of corrosion and the enhancement of the ability of self-healing of the surface ${ }^{[4]}$. The protection features of that oxide films formed spontaneously on the material oxide surface are improved by adding Mo to pure Ti.

Under the norm ASTM F 2066, the Ti-15Mo alloy was approved to be applied in devices as implants for humans $^{[5]}$. According to Rodrigues et al. (2015), a stable passive oxide film was formed on the Ti-15Mo alloy surfaces, which were exposure to naturally-aerated solutions containing chloride and fluoride ions that caused a decrease in corrosion resistance ${ }^{[6]}$. The literature

Copyright (C) 2018 Aline Varella Rodrigues et al.

doi: 10.24294/jpse.v1i4.897

EnPress Publisher LLC.This work is licensed under the Creative Commons Attribution-NonCommercial 4.0 International License (CC BY-NC 4.0). http://creativecommons.org/licenses/ by/4.0/ 
describes the increase of the corrosion potential and polarization resistance, and the decrease of the oxidation tendency when the Mo contents are added into the $\mathrm{Ti}$ alloy in sequence cp-Ti $>$ Ti-6.5Mo $>$ Ti-8.5Mo $>$ Ti- $10 \mathrm{Mo}^{[7]}$.

The aim of this work is to develop surface layers with enhanced stability against to the localized corrosion processes. Through the X-ray electron spectroscopy, the structures of $\mathrm{TiO}_{2}$ and $\mathrm{MoO}_{2}$ were characterized. The corrosion resistance was evaluated for the behaviors of cp-Ti and Ti-Mo alloys containing 6,10 and $15 \mathrm{wt} \%$ of Mo in media with chloride and fluoride ions. The solutions were prepared to simulate the commercial fluorinated gels that contain $1450 \mathrm{ppm}$ of fluoride ions ${ }^{[8]}$. In this work, the $\mathrm{pH}$ of the solutions was kept as 7, avoiding the formation of $\mathrm{TiF}_{3}, \mathrm{TiF}_{4}$ and $\mathrm{TiOF}_{2}$ which could dissolve the passive films. The addition of Mo improved the passivity and the corrosion resistance of the Ti alloys, observing their electrochemical behavior through the electrochemical techniques, such as open circuit potential and cyclic voltammetry ${ }^{[9]}$.

\section{Materials and methods}

The samples of Ti-Mo containing 6, 10 and $15 \mathrm{wt} \%$ of Mo were prepared using arc-melting furnace under ultra-pure argon atmosphere, whose procedure is well described in the literature ${ }^{[10]}$. Both $\mathrm{TiO}_{2}$ and $\mathrm{MoO}_{2}$ passive films were analyzed by XPS.

The electrochemical performances were conducted in a standard three-electrode cell. The three-electrode were built with $0.44 \mathrm{~cm}^{2}$ of exposure area in the working electrode, a platinum mesh as a counter electrode and a SCE as reference. Those measurements were performed in the naturally-aerated solutions: $0.15 \mathrm{~mol} \mathrm{~L}^{-1} \mathrm{Na}_{2} \mathrm{SO}_{4}$, $0.15 \mathrm{~mol} \mathrm{~L}^{-1}$ Ringer, $0.15 \mathrm{~mol} \mathrm{~L}^{-1}$ Ringer plus $0.036 \mathrm{~mol}$ $\mathrm{L}^{-1} \mathrm{NaF}$ and $0.036 \mathrm{~mol} \mathrm{~L}^{-1} \mathrm{NaF}$. The $0.15 \mathrm{~mol} \mathrm{~L}^{-1}$ Ringer solution was composed of $8.610 \mathrm{~g} \mathrm{~L}^{-1} \mathrm{NaCl}, 0.490 \mathrm{~g} \mathrm{~L}^{-1}$ $\mathrm{CaCl}_{2}$ and $\mathrm{KCl} 0.300 \mathrm{~g} \mathrm{~L}^{-1}$.

The experiments with the working electrodes (cp-Ti, Ti-6Mo, Ti-10Mo and Ti-15Mo) were conducted at $25{ }^{\circ} \mathrm{C}$. The working electrodes were polished with 600 grade silicon carbine paper and rinsed with distilled and deionized (Milli-Q ${ }^{\circledR}$ ) water. Both potentiostat/galvanostat Solartron Electrochemical Interface, mod. SI 1287, and Solartron Instruments HF Frequency Response Analyser, mod. SI 1255, were used to measure the open circuit potential and cyclic voltammety values. The open circuit potential measurements were carried out on fleshly-polished samples, in naturally-aerated aqueous electrolytes solutions already mentioned, immediately after polishing. These values were recorded after $1 \mathrm{~h}$, and repeated three times in order to verify the reproducibility of the technique. The cyclic voltammetry analyses were set up at a potential in the hydrogen evolution region $\left(-0.8 \mathrm{~V}\right.$ vs. SCE) by scanning at $50 \mathrm{mV} \mathrm{s}^{-1}$ towards more positive potentials up to $8.0 \mathrm{~V}$ (SCE), when the scanning was reversed towards to the initial potential. Either the open circuit potential graphs or cyclic voltammograms were obtained for cp-Ti and Ti-Mo containing 6,10 and $15 \mathrm{wt} \%$ of Mo, which were immersed in all the referred electrolytes.

After $1 \mathrm{~h}$ of Ti-Mo alloy immersion in the referred solution and the application of the electrochemical impedance spectroscopy (EIS), it was used a spectrometer UNI-SPECS UHV for the X-ray photoelectron spectroscopy measurement in order to analyze the Ti-Mo chemical structure. The line $\mathrm{Mg}$ was used ( $\mathrm{hn}=1,253.6 \mathrm{eV}$ ), and the energy step of the analyzer for high resolution spectra was set to $10 \mathrm{eV}$. The composition of the surface layer $(\sim 3 \mathrm{~nm})$ was determined with accuracy of $\pm 10 \%$, and the error of the peak positions was $\pm 0.1 \%$.

\section{Results and discussion}

The cp-Ti was used as a control in the electrochemical measurements, where the Ti-6Mo, Ti-10Mo and Ti-15Mo alloys behaviors were also performed in different electrolytic solutions simulating the naturally-aerated medium.

\subsection{Open circuit potential $\left(\mathrm{E}_{\mathrm{oc}}\right)$}

The time, when the oxide film was formed on the alloy surfaces, was measured by the spontaneous process of $E_{o c}$, showing the protection of the metal and metal alloys against the corrosion as long as the potential was raised.

The curves of $E_{o c}$ variation versus time were demonstrated for cp-Ti, Ti-6Mo, Ti-10Mo and Ti-15Mo, analyzed in solution as $\mathrm{Na}_{2} \mathrm{SO}_{4}$, Ringer, Ringer plus $\mathrm{NaF}$ and $\mathrm{NaF}$, which are depicted in Figure 1 (a), Figure 1 (b), Figure 1 (c) and Figure 1 (d), respectively. 

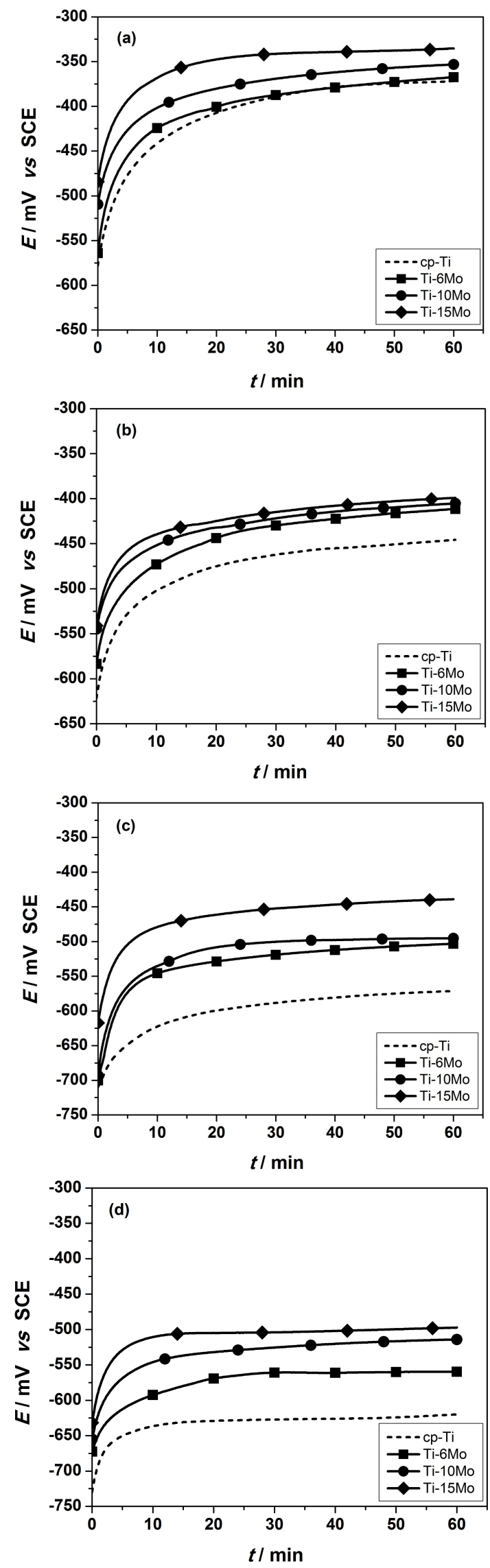

Figure 1; $\mathrm{E}_{\mathrm{oc}}$ as a function of time for $\mathrm{cp}-\mathrm{Ti}$ and Ti-Mo alloys (Ti-6Mo, Ti-10Mo and Ti-15Mo) in solutions of (a) 0.15 mol L-1 $\mathrm{Na}_{2} \mathrm{SO}_{4}$, (b) $0.15 \mathrm{~mol} \mathrm{~L}^{-1}$ Ringer, (c) $0.15 \mathrm{~mol} \mathrm{~L}^{-1}$ Ringer plus $0.036 \mathrm{~mol} \mathrm{~L}^{-1} \mathrm{NaF}$, and (d) $0.036 \mathrm{~mol} \mathrm{~L}^{-1} \mathrm{NaF}$.

The addition of Mo to cp-Ti and their alloys increased the protective properties of the metallic oxide, observed by the potential increased in the beginning of the measurements and stop raising after approximately $10 \mathrm{~min}$. The stable potentials in the open-circuit measurements are related to the formation and thickening of the oxide film on the patterns surfaces. All the samples presented the same behavior, showing the tendency to form a passive film, demonstrated by the shift of the $\mathrm{E}_{\mathrm{oc}}$ to more positive direction with the time. Either in Ringer or fluorinated solutions, the $\mathrm{E}_{\mathrm{oc}}$ for $\mathrm{Ti}-15 \mathrm{Mo}$ is more positive than that for $\mathrm{cp}$-Ti and other Ti alloys containing different Mo concentrations. This is explained by the Mo contributions in the formation of the oxide film ${ }^{[6,11]}$. There was a decrease of $E_{o c}$ in the fluorinated solution compared with the values obtained under the Ringer medium, explained by the corrosion resistance decrease, especially of the cp-Ti, caused by the fluoride ions which attack more significantly the oxide film. The values potentially less negative in Ringer meant the anodic passivation which improved the corrosion resistance of the Ti-15Mo alloy[12].

\subsection{Cyclic voltammetry (CV)}

The cyclic voltammograms were performed for investigating the dissolution kinetics of the cp-Ti and Ti-Mo alloys surfaces modification. The cyclic voltammograms, observed in Figure 2, were recorded for the Ti-6Mo, Ti-10Mo and Ti-15Mo, which were exposed in solutions as $\mathrm{Na} 2 \mathrm{SO} 4$, Ringer, Ringer plus $\mathrm{NaF}$ and $\mathrm{NaF}$ mentioned before. There were formation and growth of the anodic oxide film in the region a during the increase of the anodic current density, and the passivation of the materials in the region $b$. It was reached a current plateau and there was no transpassivation in potentials up to $8 \mathrm{~V}^{[6,13-14]}$. 

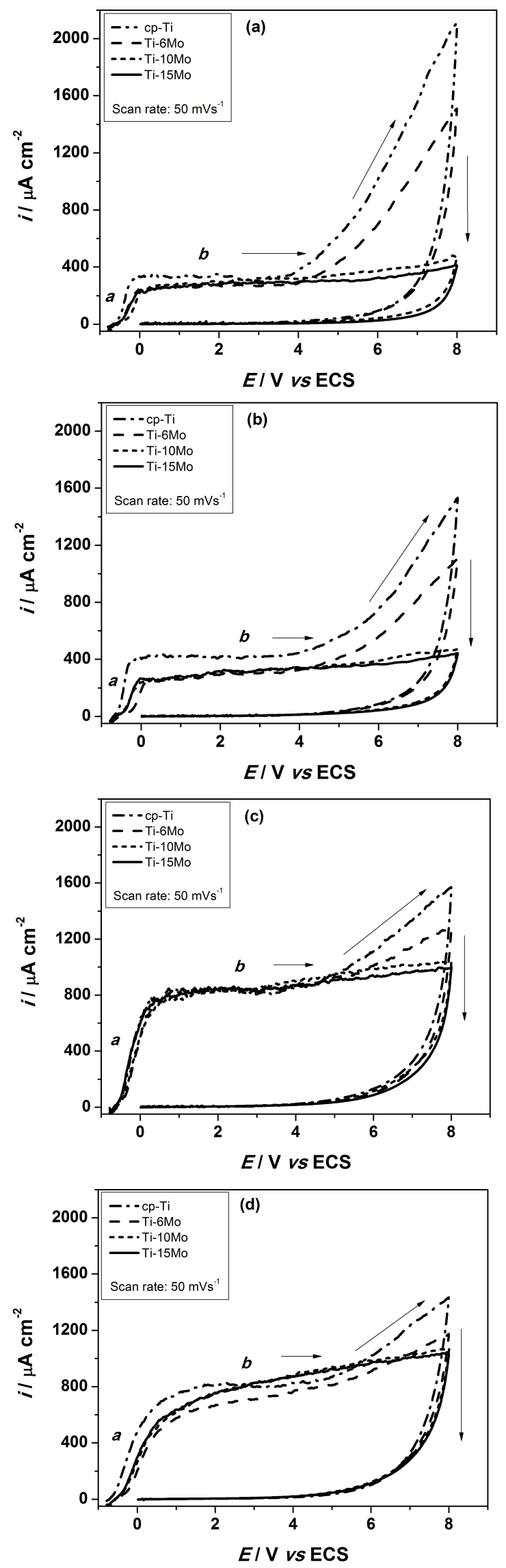

Figure 2; Cyclic voltammograms for $\mathrm{cp}-\mathrm{Ti}$ and $\mathrm{Ti}-\mathrm{Mo}$ alloys (Ti-6Mo, Ti-10Mo and Ti-15Mo) in solutions of (a) 0.15 mol L-1 $\mathrm{Na}_{2} \mathrm{SO}_{4}$, (b) $0.15 \mathrm{~mol} \mathrm{~L}^{-1}$ Ringer, (c) $0.15 \mathrm{~mol} \mathrm{~L}^{-1}$ Ringer plus $0.036 \mathrm{~mol} \mathrm{~L}^{-1} \mathrm{NaF}$, and (d) $0.036 \mathrm{~mol} \mathrm{~L}^{-1} \mathrm{NaF}$, at a scan rate of $50 \mathrm{mV} \mathrm{s}^{-1}$. Regions of $\mathrm{a}$ and $\mathrm{b}$ are related to be the formation/growth of the anodic oxide film and the passivation of Ti materials, respectively.

There was also no pitting corrosion in all the Ti-Mo alloys exposed in the different solutions during the potential scans, suggesting their high resistance even in the presence of fluoride ions, which did not avoid the formation of the passive film probably due to the small amount of HF in the solution, nevertheless these ions can dissolve the passive film due to the formation of $\mathrm{TiF}_{3}$, $\mathrm{TiF}_{4}$ and $\mathrm{TiOF}_{2}{ }^{[13]}$, expressed in the (1), (2) and (3) reactions:

$$
\begin{gathered}
\mathrm{TiO}_{2}+2 \mathrm{HF} \rightarrow \mathrm{TiOF}_{2}+\mathrm{H}_{2} \mathrm{O}(1) \\
\mathrm{TiO}_{2}+4 \mathrm{HF} \rightarrow \mathrm{TiF}_{4}+2 \mathrm{H}_{2} \mathrm{O}(2) \\
\mathrm{Ti}_{2} \mathrm{O}_{3}+6 \mathrm{HF} \rightarrow 2 \mathrm{TiF}_{3}+3 \mathrm{H}_{2} \mathrm{O}(3)
\end{gathered}
$$

At the scan of $50 \mathrm{mV} \mathrm{s}^{-1}$, the cyclic voltammograms demonstrated a passive plateau, which had a constant current density up to a potential of $4 \mathrm{~V}$ correspondent to the thickening of the oxide film, indicating the growth of anodic oxide film of $\mathrm{TiO}_{2}$ and its thickness linearly increasing with the applied potential. There was an improvement of the resistance against the corrosion processes in the Ti-15Mo alloy, especially in the media of $\mathrm{Na}_{2} \mathrm{SO}_{4}$. The values of the current density in the positive scan increased in the presence of the chloride and fluoride ions, indicating that there was a current resistance reduction of the patterns immersed in the related media. The literature has described a deleterious influence of these sorts of ions in the corrosion resistance behavior of $\mathrm{Ti}$ alloys: at high concentrations of fluoride ions, for instance, up to $10000 \mathrm{ppm}$, in a range of $\mathrm{pH}$ between 7.2 and 3.2, there is a losing of the $\mathrm{Ti}$ alloys corrosion resistance properties. It is a noticeable impact when the gels and solutions contain a concentration of fluorides relatively high in order to prevent dental caries ${ }^{[14-16]}$.

Observing all the cyclic voltammograms, it was realized that there was a rapid decrease of the current density to values close to zero during the reverse scan, without the reduction of the passive film. The current density started increasing at $4 \mathrm{~V}$, which meant the existence of a parallel reaction of water oxidation and 
release of $\mathrm{O}_{2}$. According to the Pourbaix diagram, the oxidation reactions of water above $1.2 \mathrm{~V}$ is enabled to be occurred, therefore, explaining that release of $\mathrm{O}_{2}$ close to $4 \mathrm{~V}^{[6,15]}$.

\subsection{X-ray electron spectroscopy (XPS)}

The oxide compositions formed under the Ti-Mo alloys surfaces were identified by the XPS technique, which showed the surfaces of the anodized samples containing $\mathrm{TiO}_{2}$ and $\mathrm{MoO}_{2}{ }^{[12]}$. The thickness of that oxide films was also identified after the EIS. The XPS spectra of high resolution are visualized in Figure 3 for the Ti-15Mo alloy after the EIS application under the solutions of (a) $0.15 \mathrm{~mol} \mathrm{~L}^{-1} \mathrm{Na}_{2} \mathrm{SO}_{4}$ and (b) $0.15 \mathrm{~mol} \mathrm{~L}^{-1}$ Ringer plus $0.036 \mathrm{~mol} \mathrm{~L}^{-1} \mathrm{NaF}$.

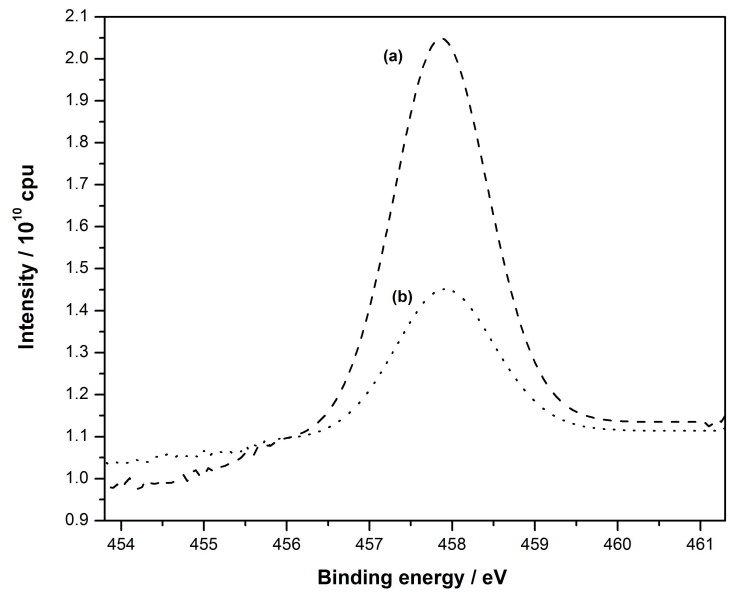

Figure 3; XPS spectrum with high resolution of $\mathrm{TiO}_{2}$ for Ti-15Mo after the EIS application under the solutions of (a) $0.15 \mathrm{~mol} \mathrm{~L}^{-1} \mathrm{Na}_{2} \mathrm{SO}_{4}$ and (b) $0.15 \mathrm{~mol} \mathrm{~L}^{-1}$ Ringer plus 0.036 mol L-1 NaF.

The $\mathrm{TiO}_{2}$ peak appeared at $458 \mathrm{eV}$, correspondent to the Ti $2 \mathrm{p}$. This peak was observed for both Ti-15Mo alloy that were kept, after the EIS application, under the solutions of $0.15 \mathrm{~mol} \mathrm{~L}^{-1} \mathrm{Na}_{2} \mathrm{SO}_{4}$ and $0.15 \mathrm{~mol} \mathrm{~L}^{-1}$ Ringer plus $0.036 \mathrm{~mol} \mathrm{~L}^{-1} \mathrm{NaF}$. The passive film was formed. The ratio between the Ti and Mo concentrations were higher as $7.6 \%$ in the medium of $\mathrm{Cl}^{-}$ions, and the least of $4.6 \%$ in that containing solely the $\mathrm{F}^{-}$ions, which attack the alloy in the passive regions, even it was formed spontaneously under the alloy surface ${ }^{[6]}$. Investigating the sorts of the passive film grown and formed on the Ti-Mo alloy surfaces, the Ti-15Mo was taken into account to be observed, once the resistance existent against corrosion processes was higher in that 15 $\mathrm{wt} \%$ of Mo concentration. After the EIS application applied on the surface of Ti-15Mo alloy, which was immersed in the solution containing both of chloride and fluoride ions simulating the physiological media, the presence of another film as $\mathrm{MoO}_{2}$ was investigated on the surface of the same passivated patterns. In the XPS spectrum with high resolution represented in Figure 4, it is also likely to observe the peaks of $\mathrm{Mo}$ and its molybdenum oxide as $\mathrm{MoO}_{2}$ : (a) Mo $3 \mathrm{~d}_{5 / 2}$, (b) Mo $3 \mathrm{~d}_{3 / 2}$, (c) $\mathrm{MoO}_{2} 3 \mathrm{~d}_{5 / 2}$, and (d) $\mathrm{MoO}_{2} 3 \mathrm{~d}_{3 / 2}$.

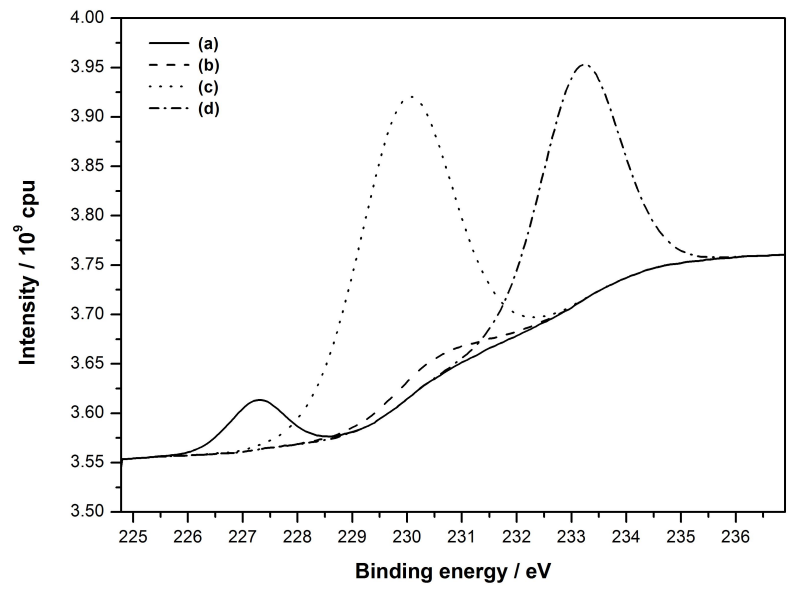

Figure 4; XPS spectrum with high resolution of Mo 3d and $\mathrm{MoO}_{2} 3 \mathrm{~d}$ for Ti-15Mo after the EIS application under the solution of $0.15 \mathrm{~mol} \mathrm{~L}^{-1}$ Ringer plus $0.036 \mathrm{~mol} \mathrm{~L}^{-1} \mathrm{NaF}$ : (a) Mo $3 \mathrm{~d}_{5 / 2}$, (b) $\mathrm{Mo} 3 \mathrm{~d}_{3 / 2}$, (c) $\mathrm{MoO}_{2} 3 \mathrm{~d}_{5 / 2}$, (d) $\mathrm{MoO}_{2} 3 \mathrm{~d}_{3 / 2}$.

It can be concluded that the obtained $\mathrm{TiO}_{2}$ and $\mathrm{MoO}_{2}$ passive films were on the cp-Ti and Ti-Mo alloys surfaces, without unoxidized metal, the same behavior found into the Ti-15Mo which used electropolishing and anodic passivation processes described in the literature $^{[12]}$.

It is known that the Mo has high solubility in $\mathrm{Ti}$ and larger atomic radius, causing the lower Young's modulus, for instance, in the Ti-12Mo- $13 \mathrm{Nb}$. By this way, the presence of larger atomic radius reduces the binding force of the Ti lattice, expanding the unit cell volume ${ }^{[17]}$. The $\mathrm{MoO}_{2}$ is the most stable film of Mo, inert and insoluble in water and alkaline media, forming solid solutions with $\mathrm{TiO}_{2}$. On the Ti-Mo alloy surface, it is the first barrier formed, therefore, the first layer attacked by the aggressive ions, explaining the least amount of Mo. The second barrier formed spontaneously is the $\mathrm{TiO}_{2}$ thin film. Despite of the fact there was a decrease of the $\mathrm{TiO}_{2}$ and $\mathrm{MoO}_{2}$ film thicknesses, there was still alloy surface protection, observed by the $\mathrm{E}_{\mathrm{oc}}$ and $\mathrm{CV}$ values ${ }^{[6,18]}$. 
According to the Sun et al. (2012), the signals in the XPS spectrum with high resolution at 230.1 and 233.3 $\mathrm{eV}$ can be attributed to the presence of $\mathrm{MoO}_{2} 3 \mathrm{~d}_{5 / 2}$ and $\mathrm{MoO}_{2} 3 \mathrm{~d}_{3 / 2}$, respectively ${ }^{[19,20]}$. And the signals of $\mathrm{Mo}$ $3 \mathrm{~d}_{5 / 2}$ and Mo $3 \mathrm{~d}_{3 / 2}$ are located at 227.3 and $230.6 \mathrm{eV}$, respectively ${ }^{[21]}$. It is realized that the band intensity of the Mo 3d correspondent to the $\mathrm{MoO}_{2}$ is much lower than that one related to the $\mathrm{Ti} 2 \mathrm{p}$ correspondent to the $\mathrm{TiO}_{2}$ because the main component of the passive film is the $\mathrm{TiO}_{2}$ in both cp-Ti and Ti-Mo alloy, once the concentration of Ti element is higher than that of $\mathrm{Mo}^{[22]}$.

\section{Conclusions}

A decrease of the corrosion resistance occurred in both the cp-Ti and Ti-Mo alloys when they were immersed in the solutions containing fluoride and chloride ions. There were formation and growth of passive films of $\mathrm{TiO}_{2}$ and $\mathrm{MoO}_{2}$ without pitting corrosion. Even the corrosion resistance was lower in the presence of fluoride ion, explained by its more aggressive attack to the surface passivated, there was the protection of all the cp-Ti and Ti-Mo alloys against the corrosion, increasing with the Mo content concentration.

\section{Author Contributions}

The authors of this paper, A V R and A C G, contributed to the academy and scientific research with the study of the corrosion protection of $\mathrm{cp}$-Ti and Ti-Mo alloys. Evidences of materials corrosion resistance improvement were proved through their electrochemical performance changing, which was took into account the authors' knowledge about the electrochemical techniques, such as open-circuit potential and cyclic voltammetry. The X-ray photoelectron spectroscopy was also applied in this work for helping the identification of the sorts of films, $\mathrm{TiO}_{2}$ and $\mathrm{MoO}_{2}$, formed on the materials surface after these ones were kept into different electrolytic solutions simulating the naturally-aerated medium. The alloys passivation was improved with the raise of Mo content concentrations. Even in the presence of aggressive environment, the corrosion resistance of the materials, in special Ti-Mo alloys, was raised without pitting corrosion occurrence.

\section{Conflict of Interest}

No conflict of interest was reported by the authors.

\section{Acknowledgments}

The authors express their sincere acknowledgments to N.T.C. Oliveira for providing the Ti-Mo alloys by using an arc-melting furnace under an ultra-pure argon atmosphere. Besides the Institute of Chemistry of UNESP University that supported this work with equipments and lab space.

\section{References}

1. Izquierdo J, Bolat G, Mareci D, et al. Electrochemical behaviour of ZrTi alloys in artificial physiological solution simulating in vitro inflammatory conditions. Applied Surface Science 2014; 313: 259-266.

2. Pina VG, Amigó V, Muñez AI. Microstructural, electrochemical and tribo-electrochemical characterisation of titanium-copper biomedical alloys. Corrosion Science 2016; 109: 115-125.

3. Fattah-Alhosseini A, Imantalab O, Ansari G. The role of grain refinement and film formation potential on the electrochemical behavior of commercial pure titanium in Hank's physiological solution. Materials Science and Engineering C 2017; 71: 827-834.

4. Fattah-Alhosseini A, Ansari AR, Mazaheri Y, et al. Effect of immersion time on the passive and electrochemical response of annealed and nano-grained commercial pure titanium in Ringer's physiological solution at $37^{\circ} \mathrm{C}$. Materials Science and Engineering C 2017; 71: 771-779.

5. Bolat $\mathrm{G}$, Mareci D, Chelariu R, et al. Investigation of the electrochemical behaviour of TiMo alloys in simulated physiological solutions. Electrochimica Acta 2013; 113: 470-480.

6. Rodrigues AV, Oliveira NTC, dos Santos ML, et al. Electrochemical behavior and corrosion resistance of Ti-15Mo alloy in naturally-aerated solutions, containing chloride and fluoride ions. Journal of Materials Science: Materials in Medicine 2015; 26(1): 1-9.

7. Xie F, He X, Cao S, et al. Influence of pore characteristics on microstructure, mechanical properties and corrosion resistance of selective laser sintered porous Ti-Mo alloys for biomedical applications. Electrochimica Acta 2013; 105:121-129.

8. Kumar S, Narayanan TSNS, Kumar SS. Influence of fluoride ion on the electrochemical behaviour of $\beta$-Ti alloy for dental implant application. Corrosion Science 2010; 52(5): 1721-1727.

9. Gonzalez JEG, Mirza-Rosca JC. Study of the corrosion behavior of titanium and some of its alloys for biomedical and dental implant applications. Journal of Electroanalytical Chemistry 1999; 471(2): 109-115.

10. Oliveira NTC, Aleixo G, Caram R, et al. Development of Ti-Mo alloys for biomedical applications: microstructure and electrochemical 
characterization. Materials Science and Engineering A 2007; 452-453: 727-731.

11. Mareci D, Chelariu R, Bolat G, et al.

Electrochemical behaviour of Ti alloys containing Mo and Ta as -stabilizer elements for dental application. Transactions Nonferrous Metals Society of China 2013; 23(12): 3829-3836

12. Babilas D, Urbańczyk E, Sowa M, et al. On the electropolishing and anodic oxidation of Ti-15Mo alloy. Electrochimica Acta 2016; 205: 256-265.

13. Oufella LS, Benchettara A. Influence of fluoride on the electrochemical behvior of a new synthesized Ti-10Ta-2Mo alloy for biomedical applications. Journal of Fundamental and Applied Sciences 2016; 8(3): 731-752.

14. Scerri A, Buhagiar J, Banfield S, et al. Corrosion behaviour of triode plasma diffusion treated and PVD TiN-coated Ti-6Al-4V in acidified aqueous chloride environments. Surface and Coatings Technololgy 2015; 280: 185-193.

15. Zhang BB, Wang BL, Li L, et al. Corrosion behavior of Ti-5Ag alloy with and without thermal oxidation in artificial saliva solution. Dental Materials 2011; 27(3): 214-220.

16. Kumar S, Narayanan TSNS. Corrosion behaviour of Ti-15Mo alloy for dental implant applications. Journal of Dentistry 2008; 36(7): 500-507.

17. Gabriel SB, Dille J, Rezende MC, et al. Mechanical characterization of Ti-12Mo-13Nb alloy for biomedical application hot swaged and aged. Materials Research-Ibero-American Journal of Materials 2015; 18(Suppl 2): 8-12.

18. Braithwaite ER, Haber J. Molybdenum: an outline of its chemistry and users. Elsevier Science: Amsterdam, 1994, Chapter 1: Occurrence, extraction, production and uses of molybdenum by E. R. Braithwaite. 20-26,40-63.

19. Sun $\mathrm{Y}, \mathrm{Hu} \mathrm{X}$, Luo W, et al. Ultrafine $\mathrm{MoO} 2$ nanoparticles embedded in a carbon matrix as a high-capacity and long-life anode for lithium-ion batteries. Journal of Materials Chemistry 2012; 22(2) 425-431.

20. Simchi H, Walter TN, Choudhury TH, et al. Sulfidation of 2D transition metals (Mo, W, Re, Nb, Ta): thermodynamics, processing, and characterization. Journal of Materials Science 2017; 52(17): 10127-10139.

21. Fedderwitz H, Groß B, Sträter H, et al. Reactive copper deposition on $\mathrm{Au}(111)$ and $\mathrm{Mo}(001)$ : role of the support in the oxidation process. Journal of Physical Chemistry C 2016; 120(14): 7591-7596.

22. Zhou YL, Luo DM. Corrosion behavior of Ti-Mo alloys cold rolled and heat treated. Journal of Alloys and Compounds 2011; 509(21): 6267-6272. 